\title{
Comprehensive assessment of metabolic syndrome among rural Bangladeshi women
}

\author{
Subrina Jesmin ${ }^{1,2^{*}}$, Md Reazul Islam ${ }^{1,2}$, A M Shahidul Islam, ${ }^{1,2}$ Md Sohag Mia ${ }^{1,2}$, Sayeeda Nusrat Sultana ${ }^{1,2}$, \\ Sohel Zaedi ${ }^{1,2,3}$, Naoto Yamaguchi ${ }^{3}$, Yoshio Iwashima ${ }^{4}$, Michiaki Hiroe ${ }^{1}$ and Tetsu Watanabe ${ }^{5}$
}

\begin{abstract}
Background: Metabolic syndrome (MS), defined as a constellation of cardiovascular disease (CVD) risk factors, is one of the fastest growing public health burdens in the Asia-Pacific region. This trend is despite the fact that people in this region are no more overweight than Europeans and Americans. Unfortunately, in South Asia, MS screening has only been performed in a few countries other than Bangladesh. Therefore the present study is designed to conduct a comprehensive screening of MS in Bangladeshi rural women, which includes estimation of prevalence and assessment of risk factor.
\end{abstract}

Methods: A total of 1535 rural Bangladesh women aged $\geq 15$ years were studied using a population based crosssectional survey. The prevalence of MS was estimated using NCEP ATP III, modified NCEP ATP III and IDF criteria.

Results: The prevalence rates of MS were 25.60\% (NCEP ATP III), 36.68\% (modified NCEP ATP III), and 19.80\% (IDF), as revealed by the present study. Furthermore, based on the NCEP ATP III criteria, $11.60 \%$ of the subjects were found to have excess waist circumference; $29.12 \%$ had elevated blood pressure, $30.42 \%$ had elevated fasting plasma glucose level, $85.47 \%$ had low HDL values and $26.91 \%$ had increased triglyceride values. Low plasma HDL level was found to be the most common abnormality in the target population and elevated waist circumference was the least frequent component.

Conclusions: The present study reveals a high prevalence of MS and its associated risk factors in rural Bangladeshi women. These findings are important in that they provide insights that will be helpful in formulating effective public health policy, notably the development of future health prevention strategies in Bangladesh.

Keywords: Metabolic syndrome X, Asia, Western, Bangladesh, Rural populations, Women

\section{Background}

Metabolic syndrome (MS) is described as a cluster of abnormalities that confers an increased risk of developing atherosclerotic cardiovascular diseases (CVD) and also type 2 diabetes mellitus (T2DM). In fact, MS is now considered as a global epidemic [1], with current estimates about $20-30 \%$ of the adult population worldwide is affected [2]. Of interest to the current study is the fact that the prevalence of these disorders (MS and CVD) among South Asians [3], a community that represents one-fifth of the global population [4], is on the rise. This development imposes a significant health

\footnotetext{
* Correspondence: jsubrina@hdrcrp.org

'National Center for Global Health and Medicine, 1-21-1 Toyama, Shinjukuku, Tokyo 162-8655, Japan
}

Full list of author information is available at the end of the article burden to the subcontinent that has limited resources. The exact cause of this health trend is currently not clear. Nonetheless, several factors are believed to be potential etiological factors in the development of MS, including increased urbanization, economic growth, irregular meal times, and lifestyle change and adoption of western diet [5]. Unfortunately, millions of people in South Asia are facing a double health burden [2] i.e., the impact of poverty-related diseases (associated with infections and nutrition) is being exacerbated by the increasing load of chronic non-communicable diseases [6]. To date there has been very few studies conducted on rural women in Bangladesh. Because of our earlier preliminary data on this population were alarming, we decided to undertake a more detailed study to investigate the metabolic syndrome in rural Bangladeshi population, 
who are mostly poor and physically active. We found a higher prevalence of diabetes among Bangladeshi women, surprisingly, even in those living in rural regions [7].

The purpose of the present study was; therefore, to evaluate the prevalence of MS, identify the set of signature risk factors of MS and CVD that are unique to South Asia. Further we will examine the correlation of MS and CVD to the socio-economic and environmental conditions, particularly in Bangladesh rural women.

\section{Methods}

\section{Participants}

In a community based cross-sectional study of rural women, a total of 1535 participants aged $\geq 15$ years were selected using stratified multistage random sampling. This sample size was sufficient enough to test the research hypothesis at $5 \%$ level of significance with a statistical power of $90 \%(\beta=0.90)$. The study uses the World Health Organization's STEPS approach (modified), which entails a stepwise collection of the risk factor data based on standardized questionnaires covering demographic characteristics, somatic illnesses, somatic and mental symptoms, medications, life style, and health-related behavior (step 1), basic physical measures (step 2) and basic biochemical investigations, such as levels of blood glucose and cholesterol (step 3). All participants gave informed consent.

The study was carried out in six village communities in Gabindagonj upazila (sub-district) of Gaibandha district. This is a district in Northern Bangladesh (currently in Rangpur division, the poorest region of the country, Bangladesh); the respondents were selected randomly after selecting the division, district, and villages. Gaibandha district was established in 1984. The district consists of 7 upazilas, 3 municipalities, 27 wards, 82 union parishads, 1101 mouzas, 56 mahallas and 1244 villages. 7 upazilas/thanas are Fulchhari, Gaibandhasadar, Gobindaganj, Palashbari, Sadullapur, Saghata, and Sundarganj. The three municipalities are Gaibandha Sadar, Gobindaganj and Sundarganj.

The demographic profiles of the communities are (year 2003): 2,117,959, i.e., males 50.26\% and females 49.74\%. Average literacy $24.3 \%$, i.e., male $31.6 \%$ and female $16.5 \%$. Women were recruited through local announcements (loudspeaker) at community level and by house-to-house visits. After recruitment, participants were interviewed and examined clinically at mobile examination center and their blood samples were collected.

Furthermore, the socio-demographic-economic status and physical activity of the participants was assessed using standard methods. Participants with the following conditions were excluded from the study: pregnancy, any acute illness, on steroidal medications or any other medications likely to cause elevated plasma glucose, suffering from chronic renal or pancreatic diseases, on hormone replacement therapy (HRT) as well as individuals with known illness like ischemic heart disease (IHD), diabetes, and hypertension, and individuals who have lived in Gabindagonj for less than 6 months.

The study was approved by the Ethical Committee of the Health and Disease Research Center of Rural Peoples (HDRCRP), Dhaka, Bangladesh. This study conformed to the principles outlined in the Helsinki Declaration, and all subjects gave their written informed consent before inclusion in the study.

\section{Anthropometry}

The following parameters were measured thrice and the mean was then determined: height $(\mathrm{cm})$, weight $(\mathrm{kg})$ and waist circumference $(\mathrm{cm})$. For measuring height, subjects were requested to stand upright on a stadiometer, with their back against the wall, eyes directed forward, without shoes and with their heels aligned together. Weight was measured to the nearest $100 \mathrm{~g}$ using a digital weighing machine that was kept on a firm flat surface and checked with 'known' weights every day. Waist circumference was measured with a nonstretchable tape at the midpoint between the lower border of the rib cage and upper border of the iliac crest. Blood pressure (BP) was measured using the standard mercury manometer and cuff, twice in the right arm in a sitting position, to the nearest $2 \mathrm{mmHg}$, with the initial reading taken at least $5 \mathrm{~min}$ after the subject was made comfortable, and again after an interval of $15 \mathrm{~min}$. The average systolic and diastolic blood pressure were then determined.

\section{Biochemical analysis}

Blood for biochemical analysis was obtained from the participants after $10-12 \mathrm{~h}$ of an overnight fast. The serum was immediately separated by centrifugation, and the concentration of triglycerides (TG) [lipoprotein lipase method; Wako Chemicals, Tokyo, Japan], total cholesterol (TC) [Cholesterol E, Wako Pure Chemical Industries, Ltd. Osaka, Japan]and its fractions [low-density lipoproteins (LDL)] and high-density lipoproteins (HDL) [high density lipoprotein (HDL)-cholesterol with the Determiner-L kit (Kyowa Co Ltd, Tokyo, Japan)] were ascertained. Fasting plasma glucose [glucose with the Hexokinase G-6-PDH kit (Wako Pure Chemical Industries Ltd, Osaka, Japan)] and insulin were also measured. LDL-cholesterol was calculated as total cholesterol-HDL-cholesterolVLDL-cholesterol; VLDL-cholesterol was calculated as $0.456 \times$ total triglyceride concentration expressed in $\mathrm{mmol} / \mathrm{L}$ (Friedewald). 


\section{Definition of metabolic syndrome}

The major components of MS include central obesity, elevated BP, dyslipidemia and impaired glucose metabolism or insulin resistance. According to the NCEP ATP III definition, MS is diagnosed when 3 or more of the following 5 components are present: (1) elevated waist circumference (WC $\geq 88 \mathrm{~cm}$ in women), (2) elevated triglyceride $(\mathrm{TG} \geq 150 \mathrm{mg} / \mathrm{dl}, \geq 1.7 \mathrm{mmol} / \mathrm{L}$ ), (3) reduced HDL cholesterol (HDL $<50 \mathrm{mg} / \mathrm{dl}$ or $<1.29 \mathrm{mmol} / \mathrm{L}$ in women), (4) elevated blood pressure ( $\mathrm{BP} \geq 130 / 85$ $\mathrm{mmHg}$ ), and (5) elevated fasting plasma glucose (FPG $\geq$ $110 \mathrm{mg} / \mathrm{dl}$ or $\geq 6.1 \mathrm{mmol} / \mathrm{L}$ ) or pre-existing diabetes mellitus (DM).

In addition to the NCEP ATP III [8] definition, we have used International Diabetes Federation (IDF) [9] and NCEP ATP III criteria modified for Asian subjects (WC $\geq 80 \mathrm{~cm}$ in women) as recommended by an American Heart Association-National Heart Lung Blood Institute (AHA/NHLBI) statement [10]. The modified NCEP ATP III criteria were the same as those of the IDF criteria except that the waist circumference criterion was non-obligatory.

\section{Socioeconomic status and variables}

Socioeconomic status (SES) has been identified as an important determinant of health across a broad range of health issues $[11,12]$. SES is a multidimensional construct that includes education, occupation, income, wealth, and residence. However, the measure of this construct in less-developed countries creates a challenge because adequate data may not be available. Therefore, inclusion of several measures of SES is advantageous because it increases the likelihood of capturing a broader and, subsequently, more informative SES constructs [12]. No previous studies of MS have explicitly examined the effect of modifying SES in the Bangladeshi context. We sought to determine whether selected SES indicator variables modify the association between various measures of MS among 1535 rural Bangladeshi women.

We considered education, family income, land ownership and living housing area as indicators of SES following Argos et al. [12] and Durkin et al. [13]. The baseline questionnaire measured years of education, family income, land ownership and living housing area for all participants.

\section{Statistical analysis}

The statistical analysis was carried out using Statistical Package for Social Sciences (SPSS Inc., Chicago, IL, version 18.0 for Windows). All quantitative variables were estimated using measures of central location (mean, median) and measures of dispersion (standard deviation and standard error). Proportions were compared using
Chi square test. Logistic regression analysis was applied to find out independent predictors for MS. All statistical tests were two-sided and performed at a significance level of $p=0.05$.

\section{Results}

The present study is, to date, one of the largest community-based and comprehensive MS surveys done on rural Bangladeshi women. A total of 1,535 females aged between 15 and 85 years were included for analysis in the present study (mean \pm SE age of $40.50 \pm 0.35$ years). Women aged 35 to 54 represented about half of the participants; whereas elderly women aged 65 and above represented only $5.15 \%$ (Figure $1 \mathrm{~A}$ ). The age-wise distribution of subjects were $13.49 \%$ (< 25 years), $19.74 \%$ (2534 years), $24.69 \%$ (35-44 years), $25.08 \%$ (45-54 years), $11.86 \%$ (55-64 years) and 5.15\% (65 years+) (Figure 1A).

\section{Prevalence of metabolic syndrome}

The prevalence rates of MS based on the three different criteria were $25.60 \%$ (NCEP ATP III), 36.68\% (modified NCEP ATP III) and $19.80 \%$ (IDF criteria) (Figure 1B). Note that analysis using modified NCEP ATP III, showed a consistently higher prevalence of the MS compared to the other two criteria, namely NECP ATP III, and IDF (Figure 1B).

\section{Demographic and clinical profile of subjects}

According to the NCEP ATP III criteria, the highest prevalence of MS in rural Bangladeshi women was $43.96 \%$ for the age group between 55 to 64 years (Figure $1 \mathrm{C})$. The incidence of MS was found to increase with age, e.g., $2.90 \%$ of those below 25 years had MS compared to $43.96 \%$ for the age group between 55 to 64 years (Figure 1C). However, due perhaps to the poor response by the 65 years + age group, the prevalence of MS in this age group was found to be lower than the age group between 55 to 64 years, a group that had the highest prevalence. Numbers of MS components increase with advancement in age; particularly two and three components for this population were observed to increase (Figure 2). Among the subjects, $4.56 \%$ females had no components of MS, while $0.78 \%$ females had all 5 components of MS.

Age classified MS characteristics shows that mean systolic and diastolic blood pressure, in rural Bangladeshi women were increasing with the advancement of age; mean cholesterol and fasting blood glucose appeared to increase till age group 45-54(Table 1). BMI was statistically significant for the age group 35-44 and age $\geq 65$ compared to the age group $<25$. WC was statistically significant for almost all age groups compared to the group age $<25$; SBP and DBP were also statistically significant for all age groups compared to the group age < 


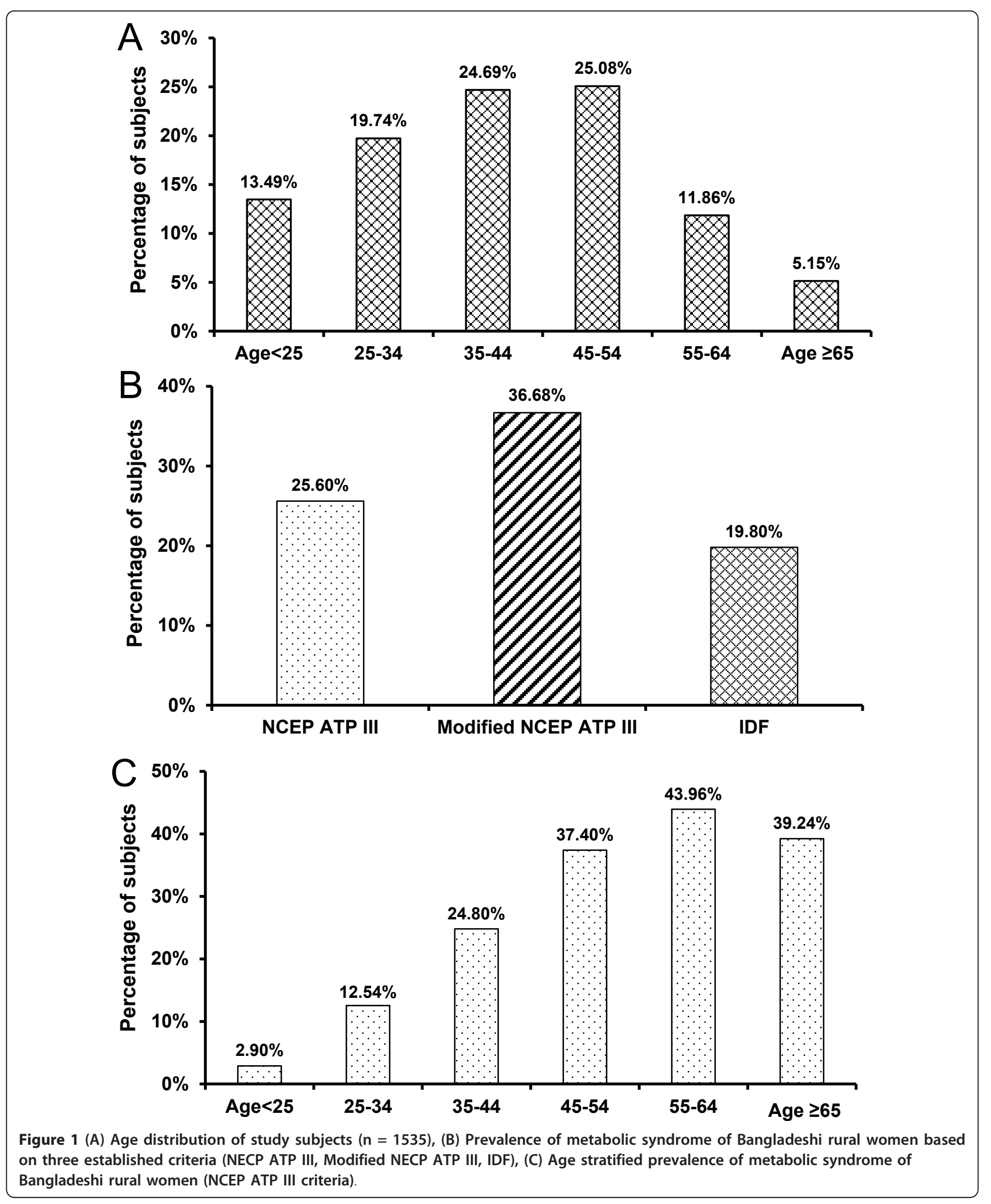




\section{Age stratified prevalence of metabolic syndrome components}

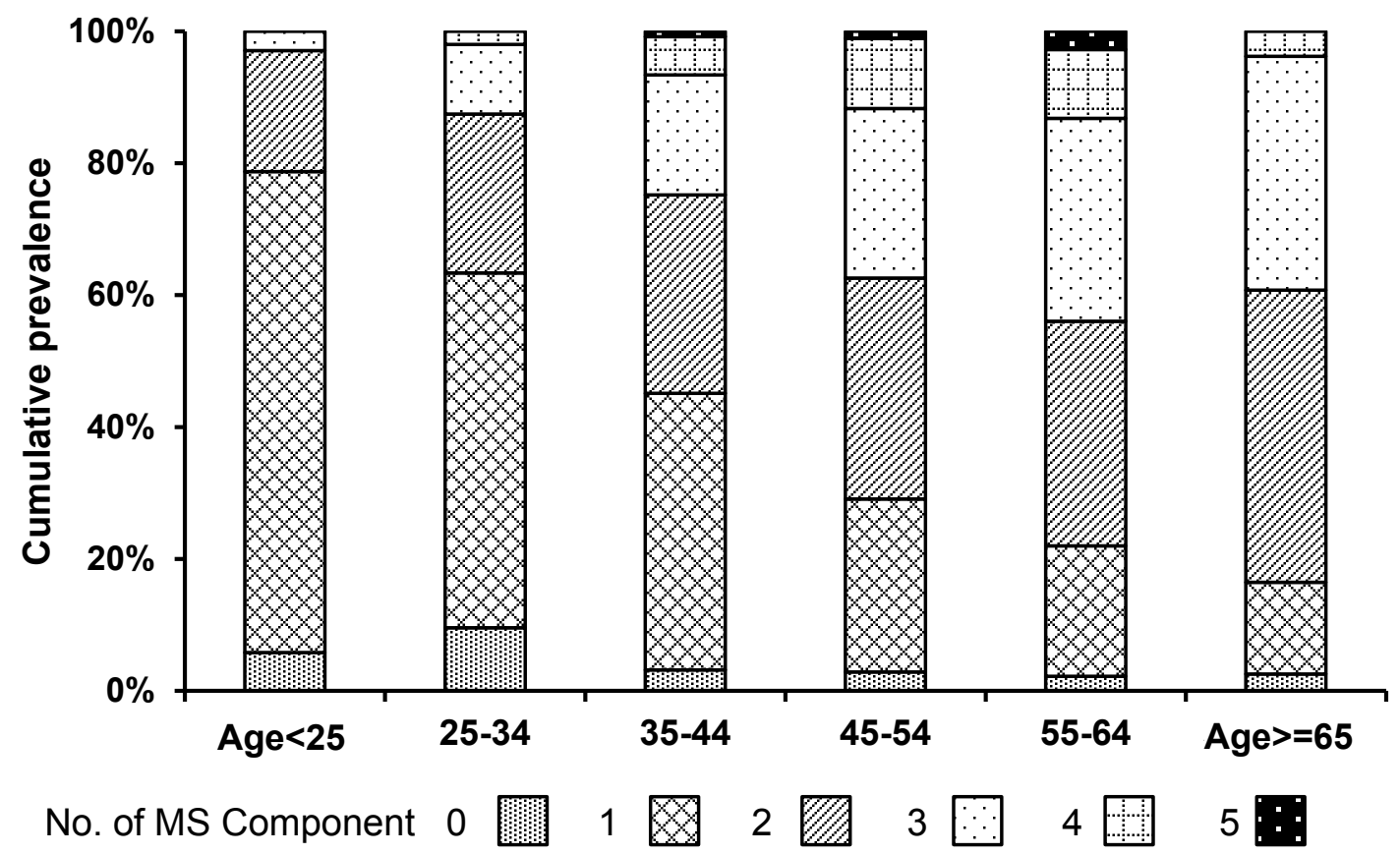

Figure 2 Age stratified prevalence of metabolic syndrome (MS) components of Bangladeshi rural women (NCEP ATP III criteria, $\mathrm{n}=$ 1535). ( 0 = no MS component present, 1 = one component of MS present, 2 = two components MS present, 3 = three components MS present, 4 = four components MS present, 5 = five components MS present).

25. Age dependent increase was significant for LDL for 45-54 age group compared to the group age $<25$. The mean fasting blood glucose has been shown to be significant for $35-44,45-54,55-64$ and $\geq 65$ age groups compared to the group age $<25$. Mean triglyceride and cholesterol levels were significant for 45-54 and 55-64 age groups compared to the group age $<25$. However, there was no statistically significant age-dependency for HDL cholesterol increase.

Table 2 shows the various socio-demographic and clinical parameters that have been compared between respondents with and without MS (as per NCEP ATP
III criteria). We found a significant difference in MS prevalence by SES indicators. MS is more common among the respondents in higher socioeconomic status (SES) than lower SES. Higher prevalence was found among the respondents with higher family income, land ownership and larger housing space (MS vs. non-MS: family income $\geq 140$ USD $5.9 \%$ vs. $2.7 \%$, family income 70-139 USD $20.9 \%$ vs. $15.6 \%$, family income $<70$ USD $73.3 \%$ vs. $77.8 \%, p=0.071$; family having land $70.5 \%$ vs. $51.8 \%$, family having no land $27.2 \%$ vs. $43.1 \%, p=<$ 0.001 ; family living area $>1,000$ sq. ft. $83.5 \%$ vs. $70.4 \%$, family living area $\leq 1,000$ sq. ft. $16.5 \%$ vs. $29.6 \%, p=<$

Table 1 Characteristics of respondents by age and MS components

\begin{tabular}{|c|c|c|c|c|c|c|c|}
\hline & Age $<25$ & $25-34$ & $35-44$ & $45-54$ & $55-64$ & Age $\geq 65$ & Total \\
\hline BMI $\left(\mathrm{kg} / \mathrm{m}^{2}\right)$ & $20.11 \pm 0.26$ & $21.26 \pm 0.23$ & $21.76 \pm 0.22^{*}$ & $21.18 \pm 0.21$ & $21.12 \pm 0.43$ & $22.25 \pm 0.61^{*}$ & $21.26 \pm 0.11$ \\
\hline Waist circumference $(\mathrm{cm})$ & $72.95 \pm 0.62$ & $77.95 \pm 0.54^{*}$ & $79.02 \pm 0.49^{*}$ & $77.53 \pm 0.49^{*}$ & $77.44 \pm 0.88^{*}$ & $74.54 \pm 0.9$ & $77.35 \pm 0.25$ \\
\hline Systolic BP (mmHg) & $98.47 \pm 0.98$ & $106.18 \pm 0.89^{*}$ & $115.36 \pm 1.02^{*}$ & $122.09 \pm 1.3^{*}$ & $132.35 \pm 2.23^{*}$ & $136.29 \pm 3.07^{*}$ & $115.62 \pm 0.62$ \\
\hline Diastolic BP (mmHg) & $67.56 \pm 0.69$ & $71.35 \pm 0.53^{*}$ & $75.61 \pm 0.51^{*}$ & $77.48 \pm 0.59^{*}$ & $81.74 \pm 1.05^{*}$ & $84.14 \pm 1.52^{*}$ & $75.16 \pm 0.3$ \\
\hline Cholesterol (mg/dL) & $153.87 \pm 5.51$ & $166.58 \pm 3.82$ & $170.29 \pm 3.48$ & $189.37 \pm 4.05^{*}$ & $187.09 \pm 5.71^{*}$ & $168.17 \pm 8.61$ & $173.88 \pm 1.89$ \\
\hline LDL cholesterol (mg/dL) & $97.09 \pm 5.23$ & $111.16 \pm 3.61$ & $110.46 \pm 3.24$ & $125.9 \pm 3.85^{*}$ & $120.95 \pm 5.44$ & $110.92 \pm 7.61$ & $113.92 \pm 1.77$ \\
\hline HDL cholesterol (mg/dL) & $33.64 \pm 0.79$ & $34.32 \pm 0.67$ & $34.87 \pm 0.56$ & $33.54 \pm 0.64$ & $33.7 \pm 1.01$ & $34.26 \pm 1.71$ & $34.13 \pm 0.31$ \\
\hline $\mathrm{TG}(\mathrm{mg} / \mathrm{dL})$ & $102.9 \pm 5.95$ & $93.59 \pm 3.69$ & $117.8 \pm 4.52$ & $139.02 \pm 5.65^{*}$ & $150.66 \pm 8.99^{*}$ & $115.32 \pm 11.24$ & $119.31 \pm 2.44$ \\
\hline Fasting blood glucose ( $\mathrm{mmol} / \mathrm{L})$ & $5.06 \pm 0.06$ & $5.39 \pm 0.09$ & $6.14 \pm 0.15^{*}$ & $6.79 \pm 0.2^{*}$ & $6.65 \pm 0.31^{*}$ & $7.07 \pm 0.36^{*}$ & $6.1 \pm 0.08$ \\
\hline
\end{tabular}

Values are represented as Mean $\pm \mathrm{SE}$; Significance level, ${ }^{*} P<0.05$ 
Table 2 Socioeconomic status of study subjects corresponding to metabolic syndrome

\begin{tabular}{|c|c|c|c|c|c|}
\hline \multirow{2}{*}{$\frac{\text { Parameters }}{\text { Family Income }}$} & \multicolumn{2}{|c|}{ Subjects without MS (\%) $n=1142$} & \multicolumn{2}{|c|}{ Subjects with MS (\%) $n=393$} & \multirow{2}{*}{$\frac{p \text { value }}{0.071}$} \\
\hline & & & & & \\
\hline Income $<70$ USD & 888 & $(77.8 \%)$ & 288 & $(73.3 \%)$ & \\
\hline Income 70-139 USD & 178 & $(15.6 \%)$ & 82 & $(20.9 \%)$ & \\
\hline Income $\geq 140$ USD & 31 & $(2.7 \%)$ & 23 & $(5.9 \%)$ & \\
\hline Missing & 45 & $(3.9 \%)$ & 0 & $(0 \%)$ & \\
\hline Own Land & & & & & $<0.001$ \\
\hline No Land & 492 & $(43.1 \%)$ & 107 & $(27.2 \%)$ & \\
\hline Land & 591 & $(51.8 \%)$ & 277 & $(70.5 \%)$ & \\
\hline Missing & 59 & $(5.2 \%)$ & 9 & $(2.3 \%)$ & \\
\hline Living Area & & & & & $<0.001$ \\
\hline Living Area $\leq 1,000$ Sqr. $\mathrm{ft}$ & 338 & $(29.6 \%)$ & 65 & $(16.5 \%)$ & \\
\hline Living Area $>1,000$ Sqr. ft & 804 & $(70.4 \%)$ & 328 & $(83.5 \%)$ & \\
\hline Education Level & & & & & 0.017 \\
\hline No Formal Education & 564 & $(49.4 \%)$ & 222 & $(56.5 \%)$ & \\
\hline Formal Education & 578 & $(50.6 \%)$ & 171 & $(43.5 \%)$ & \\
\hline Types of Work & & & & & 0.002 \\
\hline Desk Work & 28 & $(2.5 \%)$ & 20 & $(5.1 \%)$ & \\
\hline Physical Work & 1060 & $(92.8 \%)$ & 365 & $(92.9 \%)$ & \\
\hline Missing & 54 & $(4.7 \%)$ & 8 & $(2.0 \%)$ & \\
\hline Family History* of Diabetes & & & & & $<0.001$ \\
\hline Non Diabetic & 992 & $(86.9 \%)$ & 322 & $(81.9 \%)$ & \\
\hline Diabetic & 103 & $(9.0 \%)$ & 71 & $(18.1 \%)$ & \\
\hline Missing & 47 & $(4.1 \%)$ & 0 & $(0 \%)$ & \\
\hline Family History* of Hypertension & & & & & 0.003 \\
\hline Non Hypertensive & 924 & $(80.9 \%)$ & 302 & $(76.8 \%)$ & \\
\hline Hypertensive & 171 & $(15.0 \%)$ & 91 & $(23.2 \%)$ & \\
\hline Missing & 47 & $(4.1 \%)$ & 0 & $(0 \%)$ & \\
\hline Smoking Habit & & & & & 0.242 \\
\hline No & 894 & $(78.3 \%)$ & 319 & $(81.2 \%)$ & \\
\hline Yes & 248 & $(21.7 \%)$ & 74 & $(18.8 \%)$ & \\
\hline
\end{tabular}

*Family history is only accounted from father and mother only

0.001). Educated respondents without MS were more compared to those with MS (MS vs. non-MS: having formal education $43.5 \%$ vs. $50.6 \%$, having no education $56.5 \%$ vs. $49.4 \%, p=0.017$ ). Parental history of diabetes mellitus (DM) and hypertension were significantly more among those with MS than in non-MS group (MS vs. non-MS: parental history of DM $18.1 \%$ vs. $9.0 \%, p<$ 0.001 ; parental history of hypertension $23.2 \%$ vs. $15 \%, p$ $=0.003)$. However, tobacco use was not significant between MS group and non-MS group, it is rather contrasted. Current tobacco users constituted $18.8 \%$ among MS and 21.7\% among non-MS.

\section{Prevalence of individual components of metabolic syndrome}

Based on the original NCEP ATP III criteria, the most common risk factor of MS observed (Table 3) in the present study was low levels of serum HDL cholesterol, i.e., observed in $85.47 \%$ of the target population. This was immediately followed by high fasting blood glucose levels (30.42\% of the target population), high blood pressure $(29.12 \%$ of the target population) and elevated serum triglyceride levels $(26.91 \%$ of the target population). Waist circumference levels $\geq 88 \mathrm{~cm}$ were found in $11.6 \%$ of individuals. When waist circumference cut-offs were reduced based on the modified NCEP ATP III criteria, low HDL was again found to be the most common risk factor followed by elevated fasting plasma glucose level and hypertension (Table 3). It is interesting to note the sharp rise in the prevalence of central obesity, when the cut-off for waist circumference is lowered to $80 \mathrm{~cm}$ in women (11.6\% to $31.01 \%)$.

Prevalence of individual risk factors of MS that match different age groups (as per NCEP ATP III) is given in Table 3. Highest prevalence of waist circumference $(\geq$ $88 \mathrm{~cm}$ ) was observed among individuals aged between 35 to 44 years (15.83\%). Growing prevalence of TG $\geq$ $150 \mathrm{mg} / \mathrm{dl}$ was observed with advancing of age, with a 
Table 3 Age stratified prevalence of individual components of metabolic syndrome

\begin{tabular}{|c|c|c|c|c|c|c|c|}
\hline $\begin{array}{l}\text { Age } \\
\text { Group }\end{array}$ & $\begin{array}{l}\text { Obesity Waist } \\
\geq 88 \mathrm{~cm}^{* *}\end{array}$ & $\begin{array}{c}\text { Obesity } \\
\text { Waist } \geq 80 \\
\mathrm{~cm}^{*}\end{array}$ & $\begin{array}{l}\text { High TG } \geq \\
150 \mathrm{mg} / \mathrm{dl}\end{array}$ & $\begin{array}{l}\text { Low } \mathrm{HDL}< \\
50 \mathrm{mg} / \mathrm{dl}\end{array}$ & $\begin{array}{c}\text { Fasting blood } \\
\text { glucose } \geq 6.1 \mathrm{mmol} / \\
\mathrm{L}^{* *}\end{array}$ & $\begin{array}{c}\text { Fasting blood } \\
\text { glucose } \geq 5.6 \\
\mathrm{mmol} / \mathrm{L}^{*}\end{array}$ & $\begin{array}{c}\text { Hypertension (SBP } \geq 130 \\
\mathrm{mmHg} \text { or } \mathrm{DBP} \geq 85 \mathrm{mmHg})\end{array}$ \\
\hline $\begin{array}{l}\text { Age }< \\
25\end{array}$ & 2.90 & 14.98 & 14.01 & 91.79 & 7.73 & 18.36 & 1.93 \\
\hline $25-34$ & 14.19 & 40.26 & 17.49 & 87.13 & 16.17 & 29.04 & 6.60 \\
\hline $35-44$ & 15.83 & 41.16 & 25.59 & 88.92 & 29.55 & 47.23 & 24.01 \\
\hline $45-54$ & 11.69 & 29.61 & 35.32 & 84.94 & 43.38 & 56.88 & 42.86 \\
\hline $55-64$ & 12.09 & 24.18 & 43.96 & 78.02 & 41.76 & 59.89 & 59.89 \\
\hline $\begin{array}{l}\text { Age }> \\
=65\end{array}$ & 2.53 & 11.39 & 22.78 & 65.82 & 59.49 & 68.35 & 73.42 \\
\hline $\begin{array}{l}\text { All } \\
\text { age }\end{array}$ & 11.60 & 31.01 & 26.91 & 85.47 & 30.42 & 44.76 & 29.12 \\
\hline
\end{tabular}

Values are expressed in percentage

* for Modified NCEP ATP III and IDF criteria

** for NCEP ATP III criteria

difference noted in individuals aged $\geq 65$ years. However, some younger people $(<25$ years) were also found to have a very high prevalence of low $\mathrm{HDL}<50 \mathrm{mg} / \mathrm{dl}$. The prevalence of hypertension (SBP $\geq 130 \mathrm{mmHg}$ or DBP $\geq 85 \mathrm{mmHg}$ ) and elevated fasting blood glucose $\geq$ $6.1 \mathrm{mmol} / \mathrm{L}$ increase with the advancement of age (Table 3).

\section{Risk factors for metabolic syndrome}

Multivariate logistic regression analysis was used to evaluate the potential role of age, history of diabetes in parents and history of hypertension in parents in developing MS (Table 4). Advancing age emerged as one of the most significant risk factors for developing MS. Subjects in the age group 55-64 years had an odds ratio (OR) of 19.07 (CI 7.97-45.65, $p<0.001$ ) as compared to those age between 15 to 24 years. Diabetes in any one of the parents (OR 2.33, CI 1.62-3.33, $p<$ 0.001 ) was also significant independent risk factor for developing MS but hypertension in any one of the parents was not significant (OR 1.35, CI 0.99-1.84, $p=$ $0.059)$.

\section{Discussion}

The present study reports the first comprehensive MS epidemiological study that evaluated 1535 women of different age groups from rural Bangladesh. Based on three different criteria, the prevalence of MS was found to be 25.60\% (NCEP ATP III), 36.68\% (modified NCEP ATP III), and $19.80 \%$ (IDF criteria), respectively. We found a prevalence of MS that was highly age-dependent, i.e., there was an approximate four-fold increase in prevalence between age group 25-34 years to age group 55-64 years.

The prevalence of the MS in rural Bangladeshi women $(36.68 \%)$, as revealed here, is similar to that reported in rural women of India (36.4\%) using the NCEP ATP III criteria with ethnic specific cut off value for waist circumference [14]. Prevalence of MS was higher (36.68\% vs. $25.60 \%$ ) when ethnicity specific cut-offs for waist circumference were applied. Several population studies have reported an increase in the prevalence of the MS with age, regardless of definition [15-34], with some noting a peak in the seventh decade and then a decline in both sexes $[15,22,26,34]$ or only in men

Table 4 Multivariate logistic regression analysis for risk factors for metabolic syndrome (MS)

\begin{tabular}{lccc}
\hline Risk factors for MS & Odds ratio (OR) & 95\% confidence interval for OR & Significance, $\boldsymbol{p}$ \\
\hline Age groups (in years) & Reference group-age 15-24 years & & \\
$25-34$ & 3.25 & $7.33-7.95$ & 0.010 \\
$35-44$ & 7.39 & $3.15-17.37$ & $<0.001$ \\
$45-54$ & 15.16 & $6.51-35.29$ & $<0.001$ \\
$55-64$ & 19.07 & $7.97-45.65$ & $<.001$ \\
$>64$ & 16.58 & $6.44-42.67$ & \\
Family history of DM & Reference group-neither father or mother had DM & $1.62-3.33$ & \\
$\quad$ Father or mother had DM & 2.33 & & $<.001$ \\
Family history of HTN & Reference group-neither father or mother had HTN & $0.99-1.84$ & 0.001 \\
$\quad$ Father or mother had HTN & 1.35 & 0.059 \\
\hline
\end{tabular}


$[16,17,21,25,29,33]$. In the present study, the prevalence of MS increased with age but a slight decline as noted after the age of 65 years, consistent with findings reported in India [35]. The prevalence of MS was the lowest in the age group below 25 years $(2.90 \%)$, while it progressively increased with age, plateauing between 55 to 64 years $(43.96 \%)$. These findings indicate that aging may be a risk factor for MS for Bangladeshi rural women.

In the present study, based on the original NCEP ATP III criteria, low serum HDL levels was found to be the most common risk factor of MS, .i.e., it was observed in $85 \%$ of the target population. It is important to note that mean HDL levels were also found to be lower than the normal range even in the non-metabolic group (Non-MS vs. MS; $42.48 \pm 1.05,37.03 \pm 1.47$ ). When WC cut-offs specific for Asians were used as baseline for analysis, low HDL again emerged as the most common risk factor of MS followed by elevated plasma glucose level and hypertension. This observation in the pattern of profile MS in the present study is consistent with reports of previous studies performed in India $[21,36]$. These Indian studies actually demonstrate a significantly higher prevalence of low HDL cholesterol in Indian women $(90.2 \%)$ as compared to US women (39.3\%). In the present study, a consistently high prevalence (> 80-90\%) of low HDL was observed across generations, i.e., from young to old. This observation in our target population is critical considering that epidemiological studies have established a strong inverse association between HDL concentrations with increased risk of coronary artery disease. For every mg/dl decrease in $\mathrm{HDL}$, the risk for CAD increases by $2-3 \%$ [37]. However, the causality of this relationship is hard to prove [38].

Low HDL can be either monogenic or purely environmental or, in most cases is multifactorial/polygenic in origin [39]. HDL levels are under considerable genetic control with heritability estimates of up to $80 \%$ [40]. Besides, the high prevalence of low HDLC even in many individuals without obesity and hypertriglycemia, suggests an ethnic predisposition to this type of dyslipidemia. Reports of disproportionately high prevalence of low HDLC in South and Middle East Asia have been accumulating recently [41]. Gupta et al. suggested that this could be due to a high prevalence of hypoalphalipoproteinemia in the Indian population and needs to be confirmed in larger prospective studies [21]. Prevalence of high TG and low HDL-C might contribute to the high prevalence rate of MS in this study population. Metabolism and the genes associated with HDL and TG are reported, at least in part, to be linked to each other [42]. Further analysis is needed to explore the influence of life style, food pattern or physical activity of Bangladeshi rural women on such type of dyslipidemia.
The prevalence of many of the components of MS has been found to be increased over age in the present study. The prevalence of elevated fasting blood glucose and hypertension increased with age in rural Bangladeshi women. The overall prevalence of hypertension in this target population was $29.43 \%$. This hypertensive rate is higher than previously reported, i.e., prevalence of $18.2 \%$ [43]. The higher prevalence of elevated BP in our subjects may be attributed to their higher intake of saturated fat and high calorie foods. Prevalence of high blood level of TG increased, peaking between 55 to 64 years. However, in the case of HDL level there was no age-specific prevalence. These patterns in prevalence, as revealed by the present study, were similar to those in a cross-sectional population survey in urban Asian Indian adults reported by [44]. Consistent to other reports [35], we also found an age-dependent increase in the prevalence of elevated fasting plasma glucose level. Thus from the present findings, we state that age might be a strong risk factor for the high prevalence of many of the components of MS in Bangladeshi rural women although the most common prevalent component (low level of HDL) did not shown any age-specific distribution pattern.

In the present study, elevated waist circumference is the least frequent component of MS in rural Bangladeshi women based on the ATP III criteria. The average waist circumference in this population was found to be $74.80 \mathrm{~cm}$, which is consistent with another study of rural Bangladeshi women which reported a waist circumference of $68 \mathrm{~cm}$ [43]. Based on these findings, we speculate that many Bangladeshis women are metabolically obese but physically non-obese. In the present study, even when we re-evaluated our data using the modified Asian waist circumference cut-off, we still found that $18.05 \%$ of our participants did not have central obesity, even though they still had MS. Another point noteworthy is that both urban males and females had significantly higher WC and WHR (waist hip ratio) compared with their rural counter-parts, according to an Indian study by Das. This means that urban dwellers have a significantly higher central adiposity compared with rural dwellers [14]. We do not know whether there is a similar pattern in Bangladesh. We currently have an ongoing study assessing the profile of MS in Bangladeshi urban female population.

In our study, MS was significantly more prevalent among upper SES compared to lower SES which indicates SES as an emerging risk factor of MS in developing countries like Bangladesh and this finding is consistent with a study by Deepa et al., the prevalence of MS among persons belonging to middle income group was significantly higher compared to those from lower income group (18.7\% vs. 6.5\%) [45]. But it should 
be noted that the percentage of upper SES people were few in the present study population.

Few studies have demonstrated not only increased prevalence of diabetes but also other cardio metabolic risk factors including glucose intolerance and insulin resistance [46], central obesity, abnormal triglyceride and HDL among offspring of diabetic parents [47]. In our study, those with history of diabetes in either or both parents had significantly increased risk of having metabolic syndrome and other cardio metabolic risk factors including central obesity, abnormal triglyceride and HDL. Also, those whose both parents were diabetic were significantly more at risk than if only one of their parents had diabetes, thus showing evidence for genetic predisposition for developing metabolic syndrome and cardio metabolic risk factors. Similar result has been observed in a study done in 321 adolescent Indians [48]. In that study, the study subjects whose both parents had diabetes had significantly more prevalence of cardio metabolic risk factors as compared to those whose parents did not have diabetes. Thus genetic factors may play a potential role for MS development in Bangladeshi population.

The present report complements earlier MS reports performed in Bangladesh $[7,49]$. The study by Rahim was also conducted in a rural community, but in the outskirts of Dhaka city. The criteria they used to assess the prevalence of MS were modified ATP vs. IDF vs. WHO and their findings based on these criteria were $25.1 \%$ vs. 15.7 vs. 9.2\%, respectively. The figures obtained in their study were lower compared to the present study. Discrepancies in such studies are a common. For instance, the prevalence of MS in different parts of India varied from $11 \%$ to $41 \%[5,36,50]$. The underlying causes for the observed differences between studies within the same region and country may be attributed to various factors, including the type of criteria employed (EGIR, ATP III and IDF), target age groups and variation in the pattern or sets of risk factors of MS. Bhopal's findings that a large proportion (65\%) of women in Bangladesh had low HDL cholesterol level, are consistent with those of the present study [51].

In the present study, as we determined the prevalence of metabolic syndrome in Bangladeshi rural women, so we have difficulty in including the parameter work type (desk work type or physical work type) to our multivariate logistic regression analysis model. In current investigation, 45 (3.03\% of total study participants) subjects were categorized to desk work and the most of the subjects fell into physical work categories $(1345,93.27 \%$ of total study participants) and some missing cases (55 subjects, $3.7 \%$ of total subjects). More intensive investigation is warranted in future in this respect. Through a cross sectional study design it is not possible to make a concrete interpretation at this regard.

The present manuscript shows MS is an important public health problem in Bangladesh although very few studies have been done on it. The high prevalence of MS may also have serious implications for health care costs in rural Bangladesh. Thus, studies designed to examine the direct medical costs associated with MS are urgently needed.

Several steps can be taken to reduce the prevalence of potential CVD risk factors in this population. A potential initiative for dietary modifications and enhanced physical activity may have implications to reduce this public health burden [52-54]. While proper management of the individual risk factors and abnormalities of MS can reduce morbidity and mortality, a more integrated strategy will provide a better outcome. Implementation of the strategies cited here will require a community outreach. Thus, education and training of health care providers is critical. It is important to ensure that health care providers have the knowledge and skills necessary to not only treat MS patients but organized an effective MS prevention program to the community.

\section{Conclusions}

In conclusion, the present study reveals a high prevalence of MS in rural Bangladeshi women, with low serum HDL levels as the most common risk factor. These findings should prove useful in the formulation of health policies and prevention programs.

\section{Abbreviations \\ MS: Metabolic syndrome; CVD: Cardiovascular diseases; T2DM: Type 2 diabetes mellitus; BMI: Body mass index; WC: Waist circumference; HRT: Hormone replacement therapy; IHD: Ischemic heart disease; SES: Socioeconomic status; SPSS: Statistical Package for Social Sciences; WHR: waist hip ratio.}

\section{Acknowledgements}

This work was supported in part by a grant-in-aid for Scientific Research (overseas academic) from the Ministry of Education, Culture, Sports, Science and Technology of Japan (22406025) and Japan Society for the Promotion of Science. A part of this work has also been supported by research grant from Uehara Memorial Foundation (Japan).

\section{Author details}

National Center for Global Health and Medicine, 1-21-1 Toyama, Shinjukuku, Tokyo 162-8655, Japan. ${ }^{2}$ Health and Disease Research Center for Rural Peoples, Ena Arista, Flat \# B-3, House \# 802, Road \# 3, Baitul Aman Housing Society, Adabor, Dhaka 1207, Bangladesh. ${ }^{3}$ Center for Medical Sciences, Ibaraki Prefectural University of Health Sciences, Ami-machi, Inashiki-gun, Ibaraki 300-0394, Japan. ${ }^{4}$ Division of Hypertension and Nephrology, National Cardiovascular Center of Japan, 5-7-1, Fujishirodai, Suita City, Osaka, Japan. ${ }^{5}$ Department of public Health, Tokai University Graduate School of Medicine, Isehara, Japan.

\section{Authors' contributions}

SJ developed the idea for this paper; RI, SM, SI, NS and SZ performed all searches and compiled the text, SJ contributed to the writing and NY, YI, 
$\mathrm{MH}$ and TW provided conceptual and editorial input. All authors read and approved the final manuscript.

\section{Competing interests}

The authors declare that they have no competing interests.

Received: 3 September 2011 Accepted: 19 January 2012

Published: 19 January 2012

\section{References}

1. Hildrum B, Mykletun A, Hole T, Midthjell K, Dahl AA: Age-specific prevalence of the MS defined by the IDF and national cholesterol education program: the Norwegian HUNT 2 study. BMC Publ Health 2007, 7:220

2. Magat C, Goel NK, Walia DK, Agawal N, Sharma MK, Kaur J, Singh R, Singh G: Metabolic syndrome: a challenging health issue in highly urbanized union territory of north India. Diabetol Metab Syndr 2010, 2:19.

3. Eapen D, Kalra GL, Merchant N, Arora A, Khan BV: Metabolic syndrome and cardiovascular disease in south Asians. Vasc Health Risk Manag 2009, 5:731-743.

4. Gupta M, Singh N, Verma S: South Asians and cardiovascular risk: what clinicians should know. Circulation 2006, 113:e924-e929.

5. Misra A, Misra R, Wijesuriya M, Banerjee D: The metabolic syndrome in South Asians: continuing escalation and possible solutions. Indian J Med Res 2007, 125:345-354

6. Mohan V, Deepa M: The metabolic syndrome in developing countries. Diabetes Voice 2006, 51:15-17.

7. Rahim MA, Hussain A, Khan AKA, Sayeed MA, Keramat Ali SM, Vaaler S: Rising prevalence of type 2 diabetes in rural Bangladesh: a population based study. Diabetes Res Clin Pract 2007, 77:300-305.

8. Executive summary of the third report of the National Cholesterol Education Program (NCEP) Expert Panel: Detection, evaluation, and treatment of high blood cholesterol in adults (Adult Treatment Panel III). JAMA 2001, 285:2486-2497.

9. The IDF Consensus Worldwide Definition of the Metabolic Syndrome, International Diabetes Federation. 2005, [updated 2006; cited 2007 November 15]; available from: [http://www.idf.org/webdata/docs/ MetS_def_update2006.pdf.

10. Grundy SM, Cleeman Jl, Daniels SR, Donato KA, Eckel RH, Franklin BA, et al: Diagnosis and management of the metabolic syndrome: an American Heart Association/National Heart, Lung, and Blood Institute Scientific Statement. Circulation 2005, 112:2735-2752.

11. Yen $\mathrm{IH}$, Syme SL: The social environment and health: a discussion of the epidemiologic literature. Annu Rev Public Health 1999, 20:287-308.

12. Argos M, Parvez F, Chen $Y$, Hussain AZ, Momotaj H, Howe GR, Graziano JH, Ahsan $\mathrm{H}$ : Socioeconomic status and risk for arsenic-related skin lesions in Bangladesh. Am J Public Health 2007, 97:825-831.

13. Durkin MS, Islam S, Hasan ZM, Zaman SS: Measures of socioeconomic status for child health research: comparative results from Bangladesh and Pakistan. Soc Sci Med 1994, 38:1289-1297.

14. Das M, Pal S, Ghosh A: Rural urban differences of cardiovascular disease risk factors in adult Asian Indians. Am J Hum Biol 2008, 20:440-445.

15. Ford ES, Giles WH, Dietz WH: Prevalence of the metabolic syndrome among US adults: findings from the third National Health and Nutrition Examination Survey. JAMA 2002, 287:356-359.

16. Al-Lawati JA, Mohammed AJ, Al-Hinai HQ, Jousilahti P: Prevalence of the metabolic syndrome among Omani adults. Diabetes Care 2003, 26:1781-1785.

17. Azizi F, Salehi P, Etemadi A, Zahedi-Asl S: Prevalence of metabolic syndrome in an urban population: Tehran lipid and glucose study. Diabetes Res Clin Pract 2003, 61:29-37.

18. Park YW, Zhu S, Palaniappan L, Heshka S, Carnethon MR, Heymsfield SB: The metabolic syndrome: prevalence and associated risk factor findings in the US population from the Third National Health and Nutrition Examination Survey, 1988-1994. Arch Intern Med 2003, 163:427-436.

19. Villegas R, Perry IJ, Creagh D, Hinchion R, O'Halloran D: Prevalence of the metabolic syndrome in middle-aged men and women. Diabetes Care 2003, 26:3198-3199.

20. Ford ES, Giles WH, Mokdad AH: Increasing prevalence of the metabolic syndrome among US adults. Diabetes Care 2004, 27:2444-2449.
21. Gupta R, Deedwania PC, Gupta A, Rastogi S, Panwar RB, Kothari K: Prevalence of metabolic syndrome in an Indian urban population. Int J Cardiol 2004, 97:257-261.

22. DECODE Study Group, Hu G, Qiao Q, Tuomilehto J, Balkau B, BorchJohnsen K, Pyorala K: Prevalence of the metabolic syndrome and its relation to all-cause and cardiovascular mortality in non diabetic European men and women. Arch Intern Med 2004, 164:1066-1076.

23. Ilanne-Parikka P, Eriksson JG, Lindström J, Hämäläinen $H$, KeinänenKiukaanniemi S, Laakso M, et al: Finnish Diabetes Prevention Study Group Prevalence of the metabolic syndrome and its components: findings from a Finnish general population sample and the Diabetes Prevention Study cohort. Diabetes Care 2004, 27:2135-2140.

24. Jørgensen ME, Bjerregaard P, Gyntelberg F, Borch-Johnsen K: Greenland Population Study Prevalence of the metabolic syndrome among the Inuit in Greenland: a comparison between two proposed definitions. Diabet Med 2004, 21:1237-1242.

25. Adams RJ, Appleton S, Wilson DH, Taylor AW, Dal Grande E, Chittleborough C, Gill T, Ruffin R: Population comparison of two clinical approaches to the metabolic syndrome: implications of the new International Diabetes Federation consensus definition. Diabetes Care 2005, 28:2777-2779.

26. Athyros VG, Ganotakis ES, Elisaf M, Mikhailidis DP: The prevalence of the metabolic syndrome using the National Cholesterol Educational Program and International Diabetes Federation definitions. Curr Med Res Opin 2005, 21:1157-1159.

27. Boronat $M$, Chirino R, Varillas VF, Saavedra P, Marrero D, Fabregas M: NóvoaFJ: Prevalence of the metabolic syndrome in the island of Gran Canaria: comparison of three major diagnostic proposals. Diabet Med 2005, 22:1751-1756.

28. Ford ES: Prevalence of the metabolic syndrome defined by the International Diabetes Federation among adults in the US. Diabetes Care 2005, 28:2745-2749.

29. Ishizaka N, Ishizaka Y, Toda E, Hashimoto H, Nagai R, Yamakado M: Hypertension is the most common component of metabolic syndrome and the greatest contributor to carotid arteriosclerosis in apparently healthy Japanese individuals. Hypertens Res 2005, 28:27-34.

30. Lorenzo C, Williams K, Gonzalez-Villalpando C, Haffner SM: The prevalence of the metabolic syndrome did not increase in Mexico City between 1990-1992 and 1997-1999 despite more central obesity. Diabetes Care 2005, 28:2480-2485.

31. Hong Kong Cardiovascular Risk Factor Prevalence Study Steering Committee, Thomas GN, Ho SY, Janus ED, Lam KS, Hedley AJ, Lam TH: The US National Cholesterol Education Programme Adult Treatment Panel III (NCEP ATP III) prevalence of the metabolic syndrome in a Chinese population. Diabetes Res Clin Pract 2005, 67:251-257.

32. He Y, Jiang B, Wang J, Feng K, Chang Q, Fan L, Li X, Hu FB: Prevalence of the metabolic syndrome and its relation to cardiovascular disease in an elderly Chinese population. J Am Coll Cardiol 2006, 47:1588-1594.

33. Li ZY, Xu GB, Xia TA: Prevalence rate of metabolic syndrome and dyslipidemia in a large professional population in Beijing. Atherosclerosis 2006, 184:188-192.

34. Sanisoglu SY, Oktenli C, Hasimi A, Yokusoglu M, Ugurlu M: Prevalence of metabolic syndrome-related disorders in a large adult population in Turkey. BMC Public Health 2006, 6:92.

35. Deepa M, Farooq S, Datta M, Deepa R, Mohan V: Prevalence of metabolic syndrome using WHO, ATPIII and IDF definitions in Asian Indians: the Chennai Urban Rural Epidemiology Study (CURES-34). Diabetes Metab Res Rev 2007, 23:127-134

36. Misra A, Pandey RM, Devi JR, Sharma R, Vikram NK, Khanna N: High prevalence of diabetes, obesity and dyslipidaemia in urban slum population in northern India. Int J Obes Relat Metab Disord 2001, 25:1722-1729.

37. Lewington S, Whitlock G, Clarke R, Sherliker P, Emberson J, Halsey J, et al: Blood cholesterol and vascular mortality by age, sex, and blood pressure: a meta-analysis of individual data from 61 prospective studies with 55,000 vascular deaths. Lancet 2007, 370:1829-1839.

38. Linsel-Nitschke $\mathrm{P}$, Tall AR: HDL as a target in the treatment of atherosclerotic cardiovascular disease. Nat Rev Drug Discov 2005 4:193-205

39. Von Eckardstein A: Differential diagnosis of familial high density lipoprotein deficiency syndromes. Atherosclerosis 2006, 186:231-239. 
40. Boes E, Coassin S, Kollerits B, Heid IM, Kronenberg F: Geneticepidemiological evidence on genes associated with $\mathrm{HDL}$ cholesterol levels: a systematic in-depth review. Exp Gerontol 2009, 44:136-160.

41. Delavari A, Forouzanfar MH, Alikhani S, Sharifian A, Kelishadi R: First nationwide study of the prevalence of the metabolic syndrome and optimal cutoff points of waist circumference in the middle east. The national survey of risk factors for non communicable disease of Iran. Diabetes Care 2009, 32:1092-1097.

42. Holleboom AG, Vergeer M, Hovingh GK, et al: The value of HDL genetics. Curr Opin Lipidol 2008, 19:385-394.

43. Zaman MM, Choudhury SR, Ahmed J, Numan SM, Islam MS, Yoshiike N: Non-biochemical risk factors for cardiovascular disease in general clinicbased rural population of Bangladesh. J Epidemiol 2004, 14:63-68.

44. Ravikiran M, Bhansali A, Ravikumar P, Bhansali S, Dutta P, Thakur JS, et al: Prevalence and risk factors of metabolic syndrome among Asian Indians: a community survey. Diabetes Res Clin Pract 2010, 89:181-188.

45. Mohan V, Shanthirani S, Deepa R, Premalatha G, Sastry NG, Saroja R: Intraurban differences in the prevalence of the metabolic syndrome in southern India-the Chennai Urban Population Study (CUPS No. 4). Diabet Med 2001, 18:280-287.

46. Ramachandran A, Snehalatha C, Mohan V, Viswanathan M: Development of carbohydrate intolerance in offspring of Asian Indian conjugal type 2 diabetic parents. Diabetes Res Clin Pract 1990, 8:269-273.

47. Srinivasan SR, Frontini MG, Berenson GS: Longitudinal changes in risk variables of insulin resistance syndrome from childhood to young adulthood in offspring of parents with type 2 diabetes. Metabolism 2003, 52:443-450.

48. Anjana RM, Lakshminarayanan S, Deepa M, Farooq S, Pradeepa R, Mohan V: Parental history of type 2 diabetes mellitus, metabolic syndrome and cardiometabolic risk factors in Asian Indian adolescents. Metabolism 2009, 58:344-350.

49. Rahim MA, Azad Khan AK, Sayeed MA, Akhtar B, Nahar Q, Ali SMK Hussain A: Metabolic syndrome in rural Bangladesh: Comparison of newly proposed IDF, modified ATP III and WHO criteria and their agreements. Diabetes Metab Syndr Clin Res Rev 2007, 1:251-257.

50. Misra A, Khurana L: Obesity and the metabolic syndrome in developing countries. J Clin Endocrinol Metab 2008, 93:S9-S30.

51. Bhopal R, Unwin N, White M, Yallop J, Walker L, Alberti KG, et al Heterogeneity of coronary heart risk factors in Indian, Pakistani, Bangladeshi, and European origin populations: cross sectional study. $\mathrm{Br}$ Med J 1999, 319:215-220.

52. Eriksson KF, Lindgärde F: Prevention of type 2 (non-insulin-dependent) diabetes mellitus by diet and physical exercise. The 6-year Malmö feasibility study. Diabetologia 1991, 34:891-898.

53. Pan XR, Li GW, Hu YH, Wang JX, Yang WY, An ZX, Hu ZX, et al: Effects of diet and exercise in preventing NIDDM in people with impaired glucose tolerance. The Da Qing IGT and Diabetes Study. Diabetes Care 1997 20:537-544.

54. Finnish Diabetes Prevention Study Group, Tuomilehto J, Lindström J, Eriksson JG, Valle TT, Hämäläinen $H$, llanne-Parikka $P$, et al: Prevention of type 2 diabetes mellitus by changes in lifestyle among subjects with impaired glucose tolerance. N Engl J Med 2001, 344:1343-1350.

Pre-publication history

The pre-publication history for this paper can be accessed here: http://www.biomedcentral.com/1471-2458/12/49/prepub

doi:10.1186/1471-2458-12-49

Cite this article as: Jesmin et al: Comprehensive assessment of metabolic syndrome among rural Bangladeshi women. BMC Public Health 2012 12:49.

\section{Submit your next manuscript to BioMed Central and take full advantage of:}

- Convenient online submission

- Thorough peer review

- No space constraints or color figure charges

- Immediate publication on acceptance

- Inclusion in PubMed, CAS, Scopus and Google Scholar

- Research which is freely available for redistribution

Submit your manuscript at www.biomedcentral.com/submit
C) Biomed Central 